\title{
Analysis on the Influence of The Epidemic on Teaching-Learning Process in Palghar Area
}

\author{
Juita Tushar Raut ${ }^{* 1}$, Vikram Patil ${ }^{2}$ \\ ${ }^{1}$ Sonopant Dandekar College, Palghar (W), M aharashtra, India; e-mail : patiljuita@gmail.com \\ ${ }^{2}$ ADCET, Ashta, Dist-Sangali, M aharashtra, India; e-mail : vikrams.patil@gmail.com
}

\begin{abstract}
A B STRACT
The unexpected outburst of the novel COVID-19, carried a lot of damage to whole world. To contain the epidemic, people had to stay where they were. They could not go back to work places or to school or colleges. The offline courses were due to many reasons infeasible, what brought unexpected changes to education. Aside from efforts to solve this co19 problem, the state must continue to maintain the stability and sustainability of the learning process that is the right of all citizens. India experienced the same thing.

The online courses, learning process came into the picture. The influence focusses on the teaching and learning-effect, the transformation of the teaching forms. This paper mainly focussed on the impact of online-learning process on the parents. This research aims to determine how parents and their children feel about online education and also learn about their experiences.

Key Words: COVID-19, online learning, epidemic, online courses, offline courses.

SAM RIDDHI : A Journal of Physical Sciences, Engineering and Technology, (2021); DOI : 10.18090/samriddhi.v13iS1.12
\end{abstract}

\section{INTRODUCTION}

$A_{t}$

the beginning of 2020, the epidemic caused by covid-19 broke out the entire world. Because of the strong infection spread out initially at an incredible high speed, thus leading to the strict epidemic control all over world. In India, from march 2020 compulsory lock down was declared by government. Due to lock down no one can move from one location to another. At that time, the students and teachers are one of the most influenced groups. Therefore, they had to improve to learning or teaching online because the campus was locked downed. As we know that, no chance of reopen the school up to the June. Education is very important and turning point of the destiny. From the series of changes in education. Now, people want to see impact of online learning process on parents, children. This study aims to provide the peers with data and ideas of problems and solution of education under the epidemic situation. In this study, author try to covers the rural areas to figure out the online education impact on the parents as
Corresponding Author : Juita Tushar Raut, Sonopant Dandekar College, Palghar (W), Maharashtra, India; e-mail : patiljuita@gmail.com

How to cite this article : Raut, J.T., Patil, V. (2021). Analysis on the Influence of The Epidemic on Teaching-Learning Process in Palghar Area.

SAMRIDDHI : A Journal of Physical Sciences, Engineering and Technology, Volume 13, Special Issue (1), 53-56.

\section{Source of support : Nil \\ Conflict of interest : None}

well as their children. Also, analyse how they tackle the problems while learning the online. In this study, authors prepared some questions. On the basis of questionnaire authors tried to figure out how the parents and child face during this epidemic situation in palghar area.

\section{DESIGN OF QUESTIONNAIRE}

To check the fact of this study, in this research questionnaire has been developed to collect the data from the particular area. Data has been collected

OThe Author(s). 2021 Open Access This article is distributed under the term of the Creative Commons Attribution 4.0 International License (http://creativecommons.org/ licenses/by/4.0/), which permits unrestricted use, distribution, and non-commercial reproduction in any medium, provided you give appropriate credit to the original author(s) and the source, provide a link to the Creative Commons license, and indicate if change were made. The Creative Commons Public Domain Dedication waiver (http:/ /creativecommons.org/publicdomain/zero/1.0) applies to the data made available in this article, unless otherwise stated. 
from those variables that affect student learning process. Below questionnaires were distributed among Palghar area with having three different categorized board of schools.

To accomplish the purpose of the study, the following questions need to be addressed.

1. In which class your child is studying?

2. What kind of board is your child learning in?

3. What device do you use for Online Education?

4. What kind of internet access does your home have?

5. How much time your child spends each day on an average on online education?

6. Do data limit your internet access?

7. Do you face any technical issues while join the online class? If Yes, then how will you resolve it?

8. What are some positive things you have noticed about your child interaction with online learning?

9. As a parent, how would you rate the quality of online learning?

10. Which platform do you use for the online process?

11. How happy are you with the apps/platforms used for online learning?

12. How well could you manage time while onlinelearning?

13. Do you feel the communication is smooth between students and teachers?

14. Are you confident your child will make adequate academic progress through online learning?

15. How frequently do you assist your child with their schoolwork?

\section{REVIEW OF LTERATURE}

\section{CuixianNiu et al. (2017)}

This study focussed on some factors those were faced by teachers while learning in online mode. In this study, authors were developed a model of factors also build up questionnaire on the basis of some variables like teacher expectation, quality, satisfaction, complaints and teacher loyalty.

\section{Chunchen Xiao and Yi Li (2020)}

In this study, authors were mainly focussed on the impacts of the widespread on the education in china country. Authors were analysed different categories of education system like primary, secondary, post graduate, training sector and further education. After analysis of various categories of education in china, author discussed how covid-19 affects the education.

\section{Dina Fitria Murad et al. (2020)}

In this paper, authors were discussed about the impact of pandemic situation on online learning. This study also discussed about difference between online learning and face-face learning in Indonesia.

\section{METHODOLOGY}

This study is a descriptive research study using online survey method. In this survey only parents of pre-primary to senior secondary are included. In this study, limited data has been used within Palghar City. This study mainly focussed on the parents whose children are currently taking their education within Palghar City with different board of school. In Palghar, state, CBSE, ICSE boards are there.

To check the fact of this research, we used a questionnaire to collect data on the online learning that affect parents and students learning success.

The questionnaires were distributed to the parents of pre-primary to senior secondary school in Palghar Area.

\section{RESULT \& Discussion}

Analysis data of online-teaching process as shown in Table 1 . Out of the sample size, $26.5 \%$ students are studying in pre-primary section, $32.4 \%$ in primary, $38.2 \%$ in secondary and $2.9 \%$ in senior secondary section. Students are learning in various boards like $55.9 \%$ in state board, $38.2 \%$ in CBSE and $5.9 \%$ in ICSE board. Out of this sample size, after surveying the data most of the students are used smart phones for their online learning. $61.8 \%$ students are used smart phones. $29.4 \%$ students used laptop for their study, $5.9 \%$ students used desktop for their online learning and few students used tablet. For the online study most of the students access internet in their home via Wi-Fi with $70.6 \%$ and remaining students used the mobile data for their online study. After the analysis, it was found that students spend their time on online study is maximum $1-2$ Hrs means $61.8 \%$ of total data. 
Analysis on the Influence of The Epidemic on Teaching-Learning Process in Palghar Area

Some students are busy in their online lectures up to $2-3 \mathrm{Hrs}$ means $17.6 \%$ and some students spend same percentage $17.6 \%$ means $3-4 \mathrm{Hrs}$ on their study. Only few students are busy with their study more than 4 hour.

After analysis of questionnaire, it was found that most of the sample size has no data limit against their use of internet but $38.2 \%$ people have some limitation of using internet.

After analysis, it was found that many respondents face some technical issues while learning and problem can be solved by their side with the use of some tricks like restart the gadgets. Some respondents don't face such kind of issues because of some stable network. Most of the respondents found some positive changes happened inside their child due to online learning. Like self-study, more interaction with teachers, stability, IT knowledge, positiveness, improvement, eagerness, etc. But some respondents found some no change inside their child. Out of 34 respondents, $17(50 \%)$ were felt about quality of online learning was less effective and $50 \%$ were felt effective. In a survey, it was found that respondents used different kinds of platform while learning like Google meet, Microsoft Team, Zoom and other kind of platform. In that most of the respondents used meet $52.9 \%$, zoom with $20.6 \%, 8.8 \%$ of Microsoft team and 17.6 $\%$ respondent used another platform. In this online survey study, it was found that $61.8 \%$ respondents were very satisfied with their online platform but $38.2 \%$ respondents aren't satisfied. Out of 34 respondents manage their time with different levels like satisfy $26.5 \%$, average $52.9 \%$ and some of them well managed their time with $20.6 \%$. As per the survey it was found that many of respondents with $61.8 \%$ aren't feel the smooth communication between students and teachers. Out of 34 respondents, $55.9 \%$ didn't confident about children academic progress and $44.1 \%$ respondents are quite confident about their child progress. It was found that, child required $73.5 \%$ regularly support from parents within classwork. $17.6 \%$ respondents rarely assist their child and $8.8 \%$ respondents frequently assist their child while learning.
Table-1: Data analysis of online teaching-learning process

\begin{tabular}{|c|c|c|c|c|}
\hline Question No & Option A & Option B & Option C & Option D \\
\hline 1 & $26.5 \%$ & $32.4 \%$ & $38.2 \%$ & $2.9 \%$ \\
\hline 2 & $38.2 \%$ & $55.9 \%$ & $5.9 \%$ & $0 \%$ \\
\hline 3 & $29.4 \%$ & $2.9 \%$ & $5.9 \%$ & $61.8 \%$ \\
\hline 4 & $29.4 \%$ & $70.6 \%$ & - & - \\
\hline 5 & $61.8 \%$ & $17.6 \%$ & $17.6 \%$ & $2.9 \%$ \\
\hline 6 & $38.2 \%$ & $61.8 \%$ & - & - \\
\hline 7 & $73.52 \%$ & $26.47 \%$ & - & - \\
\hline 8 & $73.52 \%$ & $26.47 \%$ & - & - \\
\hline 9 & $50 \%$ & $50 \%$ & - & - \\
\hline 10 & $52.9 \%$ & $8.8 \%$ & $17.6 \%$ & $20.6 \%$ \\
\hline 11 & $61.8 \%$ & $38.2 \%$ & - & - \\
\hline 12 & $26.5 \%$ & $52.9 \%$ & $20.6 \%$ & - \\
\hline 13 & $38.2 \%$ & $61.8 \%$ & - & - \\
\hline 14 & $44.1 \%$ & $55.9 \%$ & - & - \\
\hline 15 & $17.6 \%$ & $73.5 \%$ & $8.8 \%$ & - \\
\hline
\end{tabular}

Quality of Online Learning

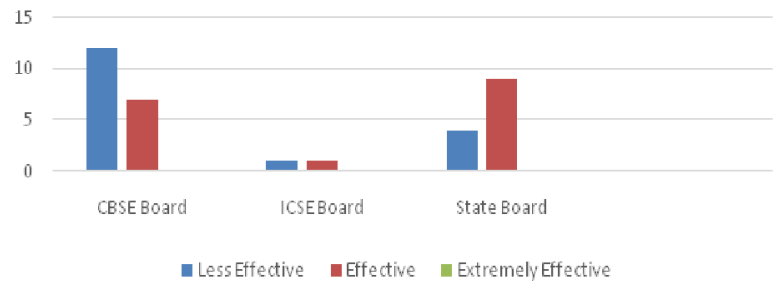

Figure 1: Quality of Online Learning

According to board where students are currently studying that we chose for this study, this paper try to figure out quality of online learning during this pandemic situation. All these categories were identified using the questionnaires. Figure No. 2 Shows that how the parents are confident about their child through online learning progress.

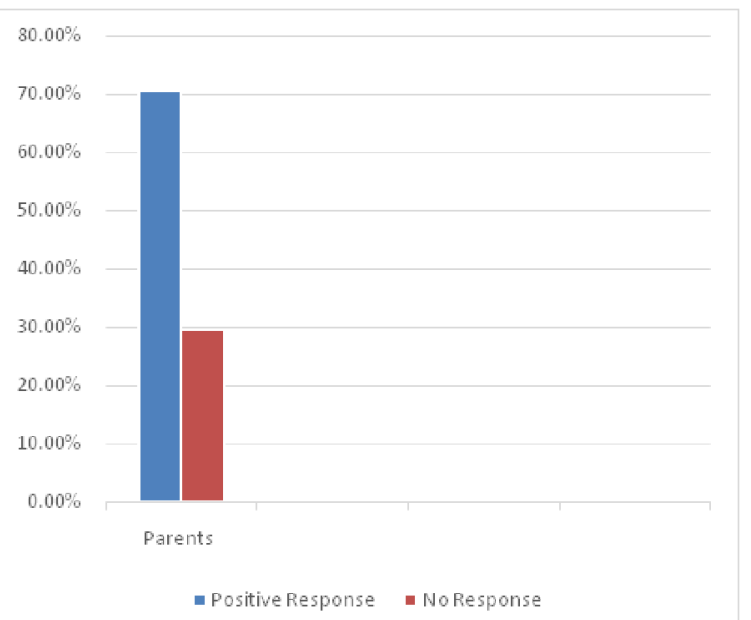

Figure 2: Positive things have noticed inside child 
Analysis on the Influence of The Epidemic on Teaching-Learning Process in Palghar Area

After analysis of the data, it has been noticed that more than $70 \%$ parents found the positiveness inside their children during this online study. Near about $30 \%$ parents were not satisfied with online study.

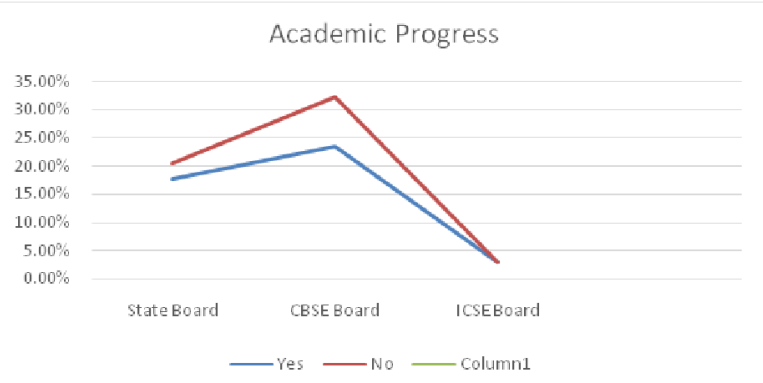

Figure 3: Academic Progress through Online Learning

According to the respondents, their child currently learned in various boards like state, CBSE, ICSE. As per their response in this study, it was cleared that, out of respondent $44.11 \%$ parents were sure about academic progress through online learning. 55.88\% parents were not sure about their children progress through online learning.

\section{CONCLUSION}

Based on the analysis and discussion of the data collected through survey it can be brief as follows:

1) Based on the results of questionnaires that have been distributed among the parents within Palghar area, which obtained some positive things that have noticed while child interact with online learning. $73.52 \%$ of respondents have noticed positiveness in their children while learning online. Like, their children acquired more IT knowledge, new learning methods, selfstudy, stabilityin their mind etc. $26.47 \%$ of respondents haven't noticed positiveness within their child.

2) Based on the respondent's data, most of the child haven't faced technical issues during online study but few students faced technical issues during online study due to slow network. But their problems were easily solved.

3) After analysis of data, it was found that $52 \%$ of respondents are felt that online study was effective and $48 \%$ of respondent said that it was less effective than offline study. Purpose of this study was to determine the satisfaction level of online learning during this pandemic situation. Education sector doesn't affect due to this situation. Online learning was tried and used in various schools that includes e-learning, google meet, zoom application, YouTube, WhatsApp social media, Microsoft Team. These amenities can be used optimally, as a medium for carrying out learning such as in classroom.

So, as long as the worth and service of the system can be sustained and fulfilment of the learner is enlarged.

\section{References}

[1] CuixianNiu et al.," A Study on Factors Affecting Satisfaction of Junior M iddle School Teachers Participating in Online Training", IEEE, Int. Conf. of Educational Innovation through Technology, 2017.

[2] S.R. Desai et al., "An Approach for Evaluating Program Educational Objectives using Indirect M ethod", IEEE, 5th IEEE International Conference on MOOCs, Innovation and Technology in Education, 2017.

[3] TantyOktavia et al., "The Influence of Social M edia to Support Learning Process in Higher Education Institution: A Survey Perspective", The International Conference on ICT for Smart Society (ICISS), ISBN: 978-1-5386-2330-5, 2017.

[4] Chunchen Xiao and Yi Li, "Analysis on the Influence of the Epidemic on the Education in China", International Conference on Big Data and Informatization Education (ICBDIE), IEEE, 2020.

[5] Dina Fitria M urad et al., "The Impact of the COVID19 Pandemic in Indonesia (Face to face versus Online Learning)", $3^{\text {rd }}$ International Conference on Vocational Education and Electrical Engineering (ICVEE), IEEE, 2020.

[6] Xuelan Zou et al., "Design of Online Teaching for Network Security Technology under Epidemic Situation", IEEE 2nd International Conference on Computer Science and Educational Informatization (CSEI), 2020.

[7] Petar Kolar et al., "Experiences with Online Education During the COVID-19 Pandemic-Stricken Semester", 62nd International Symposium ELM AR2020, 14-15 September 2020. 